\title{
Socio-Economic, Demographic and Lifestyle Determinants of Overweight and Obesity among Adults of Northeast India
}

\author{
Melody Seb Rengma ${ }^{1}$, Jaydip Sen ${ }^{2}$, Nitish Mondal ${ }^{3}$
}

\begin{abstract}
BACKGROUND: Overweight and obesity are the accumulation of high body adiposity, which can have detrimental health effects and contribute to the development of numerous preventable noncommunicable diseases. This study aims to evaluate the effect of socio-economic, demographic and lifestyle factors on the prevalence of overweight and obesity among adults belonging to the RengmaNaga population of North-east India.

METHODS: This cross-sectional study was conducted among 826 Rengma-Naga individuals (males: 422; females: 404) aged 20-49 years from the Karbi Anglong District of Assam, using a two-stage stratified random sampling. The socio-economic, demographic and lifestyle variables were recorded using structured schedules. Height and weight were recorded and the Body Mass Index (BMI) was calculated using standard procedures and equation. The WHO (2000) cut-off points were utilized to assess the prevalence of overweight $\left(B M I \geq 23.00-24.99 \mathrm{~kg} / \mathrm{m}^{2}\right)$ and obesity $\left(B M I \geq 25.00 \mathrm{~kg} / \mathrm{m}^{2}\right)$. The data were analysed using ANOVA, chi-square analysis and binary logistic regression analysis using SPSS (version 17.0).

RESULTS: The prevalence of overweight and obesity were $32.57 \%$ (males: $39.34 \%$; females: 25.50\%) and 10.77\% (males: 9.95\%; females: 11.63\%), respectively. The binary logistic regression analysis showed that age groups (e.g., 40-49 years), education $\left(\geq 9^{\text {th }}\right.$ standard), part-time occupation and monthly income $(\geq$ Rs.10000) were significantly associated with overweight and obesity $(p<0.05)$.

CONCLUSIONS: Age, education occupation and income appear to have higher associations with overweight and obesity among adults. Suitable healthcare strategies and intervention programmes are needed for combating such prevalence in population.

KEYWORDS: Overweight, obesity, occupation, income, BMI, anthropometry, Northeast India
\end{abstract}

DOI: http://dx.doi.org/10.4314/ejhs.v25i3.2

\section{INTRODUCTION}

Overweight and obesity are the physical conditions that contribute to the prevalence of numerous preventable non-communicable diseases within populations. During the last few decades, the incidence of obesity has been accelerating at an alarming rate in both the developed and developing countries (1-4). The prevalence of obesity is now being considered to be a major public health concern in many of the urban regions of the world. Even in India, which is typically known for its high prevalence of undernutrition, a considerable prevalence of overweight and obesity now co-exist among the populations (5-8). A steady increase in the prevalence of overweightobesity has been reported from different Indian populations (9-19). Recent studies have also suggested that this 'double-burden' is becoming

\footnotetext{
${ }^{1}$ Department of Anthropology, Dibrugarh University, Assam, India

${ }^{2}$ Department of Anthropology, University of North Bengal, West Bengal, India

${ }^{3}$ Department of Anthropology, Assam University, Diphu Campus, Assam, India

Corresponding Author: Dr. Nitish Mondal, E-mail: nitish_slg@rediffmail.com
} 
increasingly apparent in addition to the burden of non-communicable diseases affecting developing countries such as India $(5,8,19-20)$.

The Body Mass Index (BMI) is considered to be the most widely used derived surrogate, noninvasive and inexpensive anthropometric measure that provides a simple numeric measure of overweight and obesity (1,21-22). Several researchers have tried to establish the prevalence and relationship between overweight-obesity based on BMI in epidemiological and clinical investigations $(6,8,11,12,14,15,24-30)$.

The development of overweight and obesity is usually attributed to genetic predisposition, and it has been suggested that an obesogenic environment is considered to be a major promoting factor. The World Health Organization (WHO) has reported that individuals from both developed and developing countries consume more quantities of high energy food and exhibit less physical activity. These lead to an increase in the prevalence of overweight and obese individuals to epidemic proportions (31). Several demographic, biological, socio-economic and lifestyle factors have been shown to exhibit strong effects on excess adiposity $(8,15,26,28,31)$. It has been opined that for an effective management of the obesity epidemic is the need to understand the socio-cultural, economic, educational and environmental factors involved in the excess adiposity (overweight and obesity) (15,31). Several studies have subsequently focused on the role of such influencing factors on overweight and obesity among adult populations $(6,8,11,16,19,32)$. The determination of these potential risk factor(s) that appear to have effects on excess adiposity may be very constructive to design intervention and prevention strategies and very challenging task to researchers focusing on population investigations. Moreover, it is a rather difficult proposition to identify the determinant factor(s) of higher adiposity among different populations.

This study is based on the hypothesis that advancement of socio-economic status, attainment of higher education and lifestyle modifications can play a potential role in the increase in adiposity pattern among adult individuals. This study further tries to evaluate the effects of certain socioeconomic, demographic and lifestyle-related factors that have potential associations with the prevalence of overweight and obesity.

\section{MATERIALS AND METHODS}

Subjects and area of study: This cross-sectional study was carried out among adult individuals (aged 20-49 years) belonging to the Rengma-Naga population residing in the Karbi-Anglong district of Assam, North-east India. This district covers an area of $10,434 \mathrm{~km}^{2}$ with a total population of 965,280 individuals. All the individuals were residents of the urban and sub-urban areas in Diphu Town and the villages of Jongpha, Choshenlari and Lolashongnyu. The selection of these areas was based on the population strength, dominance and homogeneity and easy road accessibility. Ethnically, the "Rengma-Naga" is an indigenous population predominantly inhabiting the Rengma Hills of Assam, North-east India. They belong to one of the Mongoloid stocks and are classified under the Tibeto-Burman speaking group (33). A two-stage stratified random sampling method was utilized to identify the subjects. However, no such design effect was considered in order to avoid the use of the more complex design in the sampling procedures. In the first stage, the households of those individuals belonging to the Rengma-Naga population were identified based on the surnames, physical and cultural features and also verified from the official records. In the second stage, simple random sampling was utilized to select those RengmaNaga individuals constituting the age group of 2049 years.

The minimum number of individuals required for reliably estimating the prevalence of overweight-obesity was calculated following the standard sample size estimation method (34). In this method, the anticipated population proportion of $50 \%$, absolute precision of $5 \%$ and confidence interval of $95 \%$ are taken into consideration. The minimum sample size estimated for each sex was 384 individuals. The estimated minimum sample size was, therefore, $768(384 \times 2)$. A total of 880 (males: 450; females: 430) apparently healthy adults were initially approached for participation and also in order to achieve the minimum sample size. Of these 880 individuals, 54 of them (males: 28; females: 26) declined to participation in the study. Therefore, the final study sample consisted of 826 individuals (males: 422; females: 404) aged 20-49 years who voluntarily consented to participate in the study. An informed consent was 
also obtained from each individual prior to collection of data. The final sample size was observed to be higher than the minimum number of individuals required for achieving the objectives of the study. The ages of the individuals were verified from birth certificates and official documents. The individuals were free from any physical deformities and were not suffering from any disease during data collection. Pregnant, postpartum women and lactating mothers were also excluded.

A structured schedule was utilized to obtain the relevant socio-economic, demographic and lifestyle-related data such as age, sex, education, occupation, marital status, monthly income, alcohol consumption and tobacco use. The data were collected from September 2011 to July 2012. All necessary study approvals were taken from the local community leaders, village headmen and the competent authorities before the commencement of the study. The study was conducted in accordance with the ethical guidelines for human experiments as laid down in the Helsinki Declaration (35).

Anthropometric measurements recorded: The anthropometric measurements of weight and height were recorded following standard procedures (36). Weight was recorded to the nearest $0.10 \mathrm{~kg}$ with the subject standing motionless on a portable weighing scale. Height was measured to the nearest $0.10 \mathrm{~cm}$ using an anthropometer with the subject standing in the erect position with the head oriented in the Frankfort horizontal plane. The technical error measurement $\left(\mathrm{TEM}=\sqrt{ }\left(\Sigma \mathrm{D}^{2} / 2 \mathrm{~N}\right)\right) \quad(\mathrm{D}=$ difference between the measurements, $\mathrm{N}=$ number of individuals measured) was utilized to determine the accuracy of the measurements recorded (37). To calculate TEM, height and weight were recorded separately by two of the authors (MSR and NM) among 50 Rengma-Naga individuals not covered in this study. Appreciable high values were obtained $(R>0.98)$ for both intra-observer and inter-observer TEM analysis. As these values were observed to be within the cut-off values of 0.95 (37), the measurements recorded by both these authors were reliable and reproducible. All the measurements in the course of the study were subsequently recorded by them.

Assessment of overweight and obesity: The BMI was calculated using the equation:
BMI $\left(\mathrm{kg} / \mathrm{m}^{2}\right)=$ Weight $(\mathrm{kg}) / \operatorname{Height}^{2}\left(\mathrm{~m}^{2}\right)$.

The proposed criterion for overweight and obesity among the Asian populations and these cut-offs of overweight: $\geq 23.00-24.99 \mathrm{~kg} / \mathrm{m}^{2}$; obesity: $\geq 25.00 \mathrm{~kg} / \mathrm{m}^{2}$ were utilized to assess their prevalence (1). For combined overweight-obesity, the cut-off was $\geq 23.00 \mathrm{~kg} / \mathrm{m}^{2}$. Several studies have utilized these cut-offs to assess the prevalence of overweight and obesity among Indian populations (19,38-40).

Statistical analysis: All the statistical analyses were done using the Statistical Package for Social Science (SPSS Inc., Chicago,IL, version, 17.0). One way analysis of variance (ANOVA) was used to assess sex-differences in the anthropometric variables. The $2 \times 2$ Chi-square $\left(\chi^{2}\right)$ analysis was utilized to assess sex-age specific differences in the prevalence of overweight and obesity. Binary logistic regression (BLR) analysis using enter method was fitted to estimate the odds ratios (ORs) and 95\% confidence intervals (CIs) so as to examine an individual being overweight (BMI $\left.23.00-24.99 \mathrm{~kg} / \mathrm{m}^{2}\right)$ and obese $\left(\mathrm{BMI} \geq 25.00 \mathrm{~kg} / \mathrm{m}^{2}\right.$ ) and allowing controlling for the determinant variables, separately. This regression model allows for controlling the determinant variables by comparing with a reference category. The dependent variables were created by those individuals observed to be overweight and obese in regression model, separately. Discrete BLR analysis was performed for all of the determinant variables that could be associated with the prevalence of overweight and obesity. The predictor variables of sex, age, marital status, education, occupation, tobacco use, alcohol consumption and monthly income were entered into the regression models as a set of categorical variables, and results were obtained by comparing them with the reference categories. The p-values of $<0.05$ and $<0.01$ were considered to be statistically significant.

\section{RESULTS}

The sex-specific descriptive statistics of the anthropometric variables among the Rengma-Naga individuals are shown in Table 1 . The mean weight and height were significantly higher among males than females $(p<0.01)$. A slightly greater mean BMI was found among males $\left(22.66 \pm 2.07 \mathrm{~kg} / \mathrm{m}^{2}\right)$ as compared to females $\left(22.30 \pm 2.43 \mathrm{~kg} / \mathrm{m}^{2}\right)$ 
$(\mathrm{p}<0.05)$. Using ANOVA, the sex differences in statistically significant $(\mathrm{p}<0.01)$ (Table 1$)$. height, weight and BMI were observed to be

Table 1: Descriptive statistics (mean \pm standard deviation) of the anthropometric variables among the Rengma-Naga individuals

\begin{tabular}{ccccc}
\hline $\begin{array}{c}\text { Anthropometric } \\
\text { Variables }\end{array}$ & $\begin{array}{c}\text { Male } \\
(\mathrm{N}=422)\end{array}$ & $\begin{array}{c}\text { Female } \\
(\mathrm{N}=404)\end{array}$ & F-value & p-value \\
\hline Height $(\mathrm{cm})$ & $162.15 \pm 8.21$ & $156.08 \pm 8.30$ & 111.51 & 0.000 \\
Weight $(\mathrm{kg})$ & $59.53 \pm 6.84$ & $54.37 \pm 7.58$ & 105.87 & 0.000 \\
\hline BMI $\left(\mathrm{kg} / \mathrm{m}^{2}\right)$ & $22.66 \pm 2.07$ & $22.30 \pm 2.43$ & 5.22 & 0.023 \\
\hline
\end{tabular}

Prevalence of overweight and obesity: The prevalence of overweight and obesity among the Rengma-Naga individuals is depicted in Table 2. The overall prevalence of overweight (BMI 23.00$24.99 \mathrm{~kg} / \mathrm{m}^{2}$ ) and obesity (BMI $\geq 25.00 \mathrm{~kg} / \mathrm{m}^{2}$ ) was observed to be $32.57 \%$ and $10.77 \%$, respectively. The sex-specific prevalence of overweight was observed to be higher among males $(39.34 \%)$ than among females (25.50\%). The prevalence of obesity was documented to be higher among females than among males (11.63\% and $9.95 \%)$. A significant sex difference was observed in the overall prevalence of overweight $\left(\chi^{2}=9.21\right.$; d.f. 1 , $\mathrm{p}<0.01)$. However, this difference was statistically insignificant in the overall prevalence of obesity $\left(\chi^{2}=0.49\right.$; d.f. $\left.1, \mathrm{p}>0.05\right)$ (Table 2$)$. The agespecific prevalence of overweight and obesity was observed to be higher in ages of 40-50 years and 30-39 years, respectively. Lower prevalence of overweight and obesity was observed among individuals aged 20-29 years. The age-specific differences in the overall prevalence of overweight $\left(\chi^{2}=15.44 ;\right.$ d.f. $\left.2 ; p<0.01\right)$ and obesity $\left(\chi^{2}=6.18\right.$; d.f. $2, \mathrm{p}<0.05)$ were statistically significant (Table 2).

Table 2: Prevalence of overweight and obesity among the Rengma-Naga individuals

\begin{tabular}{lcccc}
\hline \multicolumn{1}{c}{ Excess Adiposity } & Male & Female & Total & Sex difference \\
& $(\mathrm{N}=422)$ & $(\mathrm{N}=404)$ & $(\mathrm{N}=826)$ & $\left(\chi^{2}\right.$-value $)$ \\
\hline Overweight (BMI 23.00-24.99 kg/m²) & $166(39.34)$ & $103(25.50)$ & $269(32.57)$ & $9.21^{* *}$ \\
Obese (BMI $\left.\geq 25.00 \mathrm{~kg} / \mathrm{m}^{2}\right)$ & $42(9.95)$ & $47(11.63)$ & $89(10.77)$ & 0.49 \\
\hline Combined overweight $\left(\mathrm{BMI} \geq 23.00 \mathrm{~kg} / \mathrm{m}^{2}\right)$ & $208(49.29)$ & $150(37.13)$ & $358(43.34)$ & $4.93^{*}$ \\
\hline
\end{tabular}

Values in parenthesis indicates percentages, *p<0.05; **p<0.01

Binary logistic regression analysis and effect of socio-economic, demographic and lifestylerelated determinants on overweight and obesity: The BLR model was fitted to find out the odds for the socio-economic, demographic and lifestyle related variables for being overweight $\left(23.00-24.99 \mathrm{~kg} / \mathrm{m}^{2}\right)$ and obese $\left(\geq 25.00 \mathrm{~kg} / \mathrm{m}^{2}\right)$ (Table 3). The results indicated that most of the socio-economic variables except marital status $(p>0.05)$ were significantly associated with overweight $(p<0.05)$. The results of the BLR analysis further showed significant effects to being overweight among females, age group of 40-49 years, education level of $\geq 9^{\text {th }}$ standard, tobacco use and alcohol consumption $(\mathrm{p}<0.05)$. A two-fold risk was observed in 40-49 years, part-time occupation and monthly income of $\geq$ Rs. 10000 categories $(p<0.01)$ with the prevalence of overweight. The results also showed that those adults belonging to the higher monthly income 
category ( $\geq$ Rs.10000) (Odds: 3.44), age-groups of 30-39 years (Odds: 2.31), education level $\geq 9^{\text {th }}$ standard (Odds: 2.39) and part-time occupation (Odds: 2.42) exhibited significantly greater odds for being obese $(p<0.01)$. The odds were observed to be greater for being obese among females, married individuals and alcohol consumers and lower in tobacco use $(\mathrm{p}>0.05)$.

Table 3: Binary logistic regression (BLR) analysis and socioeconomic, demographic and lifestyle determinants of overweight and obesity among the Rengma-Naga individuals

\begin{tabular}{|c|c|c|c|c|c|c|c|}
\hline \multirow[t]{2}{*}{ Variables } & & \multicolumn{3}{|c|}{ Overweight $\left(\geq 23.00-24.99 \mathrm{~kg} / \mathrm{m}^{2}\right)$} & \multicolumn{3}{|c|}{ Obesity $\left(\geq 25.00 \mathrm{~kg} / \mathrm{m}^{2}\right)$} \\
\hline & & Wald & Odds & $95 \% \mathrm{CI}$ & Wald & Odds & $95 \% \mathrm{CI}$ \\
\hline \multirow[t]{2}{*}{ Sex } & Male ${ }^{\circledR}$ & - & 1 & - & - & - & - \\
\hline & Female & 17.79 & $0.52 * *$ & $0.39-0.71$ & 0.61 & 1.19 & $0.77-1.85$ \\
\hline \multirow[t]{3}{*}{ Age } & 20-29 years $®$ & - & 1 & - & - & 1 & - \\
\hline & 30-39 years & 3.41 & 1.46 & $0.98-2.18$ & 7.37 & $2.31 * *$ & $1.26-4.21$ \\
\hline & 40-49 years & 27.26 & $2.69 * *$ & $1.85-3.90$ & 5.30 & $1.76^{*}$ & $0.92-3.06$ \\
\hline Marital & Unmarried $®$ & - & 1 & - & - & 1 & - \\
\hline Status & Married & 1.89 & 1.28 & $0.90-1.82$ & 0.23 & 1.14 & $0.67-1.94$ \\
\hline \multirow[t]{2}{*}{ Education } & $\leq 8$ standard ${ }^{\circledR}$ & - & 1 & - & & 1 & - \\
\hline & $\geq 9^{\text {th }}$ standard & 9.79 & $1.61 * *$ & $1.19-2.16$ & 12.46 & $2.39 * *$ & $1.47-3.88$ \\
\hline \multirow[t]{2}{*}{ Occupation } & Fulltime ${ }^{\circledR}$ & - & 1 & - & - & 1 & - \\
\hline & Part-time & 22.73 & $2.26 * *$ & $1.61-3.17$ & 13.95 & $2.42 * *$ & $1.52-3.85$ \\
\hline Tobacco & Never ${ }^{\circledR}$ & - & 1 & - & - & 1 & - \\
\hline Use & Occasional/Regular & 7.29 & $1.50 * *$ & $1.12-2.02$ & 0.87 & 0.80 & $0.51-1.27$ \\
\hline Alcohol & Never ${ }^{\circledR}$ & - & 1 & - & - & 1 & - \\
\hline Consumption & Occasional/Regular & 5.14 & $1.44 *$ & $1.05-1.98$ & 0.20 & 1.12 & $0.69-1.80$ \\
\hline Monthly & $<$ Rs. $10000 \AA$ & - & 1 & - & - & 1 & - \\
\hline Income & $\geq$ Rs. 10000 & 29.75 & $2.28 * *$ & $1.70-3.07$ & 25.96 & $3.44 * *$ & $2.14-5.53$ \\
\hline
\end{tabular}

( Reference category, CI: confidence intervals, ${ }^{*} p<0.05,{ }^{* *} p<0.01$

\section{DISCUSSION}

Sexual dimorphism in body adiposity has important implications for both clinical and epidemiological research and the differences leads to develop the risks of obesity and several metabolic disorders. The health risks associated with increasing BMI are continuous, and the interpretation of BMI grading in relation to risk may differ with respect to populations (10-14). There has been a growing debate on whether the need to develop a separate BMI cut-offs for different ethnic populations due to the increasing evidences pointing towards the differences in mortality and morbidity risk associations between BMI and body fat percentage distributions (1012,38-40). Studies have shown the association of socio-economic status with obesity that is mostly prevalent in higher socio-economic groups in the developed countries $(8,15)$. This was primarily attributed due to the fact that these populations have become increasingly independent on market 
economies and their duties and activity levels have changed from those associated with subsistence based economy to one more depended on wage labour and industrial products (41). The shift in obesity was observed towards the poorer groups and tended to be greater among women than among men in developing countries $(4,6,8,19)$. The prevalence of obesity is more common among the middle-aged individuals belonging to higher socio-economic status and those living in urban-affluent societies $(5-8,19)$. Studies have confirmed that sudden urbanization has increased the prevalence of obesity in the developing countries, while in the developed countries, the prevalence was higher in the rural areas $(8,10,11,14,15,19)$.

Recent trends suggest that the prevalence of obesity is an increasing phenomenon. Rapid urbanization, socio-economic development, modification of occupation and lifestyle have influenced its prevalence among various Indian populations. A comparative evaluation of overweight-obesity as reported from different Indian populations showed that the prevalence observed in the present study was lower than those reported for Bengalee (13) and Punjabi (42). The prevalence of overweight-obesity in the present study was observed to be higher than those reported among adults of North-India (overweight-obesity: $16.40 \%$; obesity: $5.10 \%$ ) (18). A recent study reported lower prevalence of overweight $(25.10 \%)$ and obesity $(2.00 \%)$ among Tangkhul Nagas of North-east India (16). A large scale Indian survey also reported a lower prevalence of overweight and obesity among individuals aged $15-49$ years $(9.8 \%$ versus $2.8 \%)$ (43). A higher prevalence of obesity $(19.50 \%)$ and lower prevalence of overweight $(22.00 \%)$ was reported among Bengalee adults from West Bengal (19).

The present study has observed that obesity was slightly higher among the women than men ( $p>0.05)$. It also reports significantly lower and slightly greater odds among women in overweight $(p<0.01)$ and obesity $(p>0.05)$, respectively. Several studies have conformed that the prevalence of obesity was higher among females than males $(10-16,18,19)$. The prevalence of overweight and obesity were significantly higher in middle-age groups than in lower ages $(p<0.05)$. An increase in the prevalence describing the age- related effect on adiposity has been well documented $(19,44,45)$. The odds of overweight and obesity was significantly higher in 30-39 years and 40-49 years $(p<0.05)$ (Table 3$)$. The amount of muscle-mass begins to decrease and the proportion of adiposity continuously increases with age increases (45). The increase in the odds of overweight and obesity could be thus related to age-affected body adiposity $(19,26)$. Therefore, individuals belonging to the higher age groups have greater adiposity that leads to a higher prevalence of overweight-obesity $(19,26,45)$.

The association of socio-economic variables with overweight and obesity was already reported $(6,8,46)$. Income was the primary socio-economic indicator associated with adiposity in the developing countries, while it was an education in the developed countries $(6,15)$. Results of the BLR analysis showed that individuals belonging to higher income group (Rs. $\geq 10000$ ) significantly exhibited 3.44 times and 2.88 times higher odds $(p<0.01)$ to being obese and overweight when compared with those belonging to lower income group (Rs.<10000), respectively (Table 3). It was observed that adults of higher monthly income category (Rs. $\geq 10000)$ exhibited two-fold greater risks of being overweight and obese among adults of West Bengal, India (19). It has been suggested that the average levels of the state's economic development were strongly associated with obesity among married Indian women (8). Studies have also reported that education had an inverse risk of adiposity among adults (19,47-50). The prevalence of higher adiposity was observed greater for those individuals with primary education among Malaysian adults (51). The odds were observed to be 1.61 times and 2.39 times significantly greater among Rengma-Naga individuals belonging to education level of $\geq 9^{\text {th }}$ standard to being overweight and obese, respectively $(\mathrm{p}<0.01)$ (Table 3$)$. This finding of the present study confirms the significant effect with overweight-obesity and education, as reported in the aforementioned studies.

Occupation, physical activity and sedentary lifestyle have direct influences in the prevalence of overweight and obesity as they tend to increase adiposity among adults in question. It has been reported that individuals having less physical activity and sedentary lifestyle show greater overweight-obesity $(15,19,52)$. The present study 
has shown that individuals engaged in part-time occupations showed more than two-fold risks of being both overweight and obese $(p<0.05)$. It was reported that individuals engaged in business, vocational and clerical works, those being more literate and those in the higher socio-economic category were significantly associated with obesity in Nepal (53). The worldwide increase in the prevalence of obesity has led to a focus on the lifestyle choices that may be contributed to excess energy intake, including the widespread belief that alcohol consumption was a significant risk for development (54). The increase in adiposity with alcohol consumption has been advocated in many studies $(19,25,50)$. Recent studies have also indicated that alcohol consumption exhibited increased odds among African American (55) and Chinese adults (56). The results of the present study have shown that alcohol consumption had significantly 1.44 fold greater odds to being overweight $(\mathrm{p}<0.05)$. It has also been observed that smoking and greater adiposity are strong, independent health risks but are interrelated. The smoking is associated with a lower BMI and cessation of smoking is associated with increased adiposity, and a substantial increase in waist circumference (57). An inverse relationship between smoking and adiposity has been documented, but effects of smoking on obesity remain inconclusive $(19,58)$ but a significantly greater risks (1.50 times) for overweight observed in tobacco use $(\mathrm{p}<0.05)$ (Table 3$)$.

In conclusion, the prevalence of obesity within a population is considered a risk factor for non-communicable diseases. Furthermore, economic development, nutritional transition, improved socio-economic status and an increasingly sedentary lifestyle have contributed to an increasing prevalence of overweight and obesity. There arises a need to address the challenges of establishing measures that would reduce the future ill-effects of overweight-obesity related morbidity. The results of the present study suggested that age, education, occupation and higher income have significantly greater effects on overweight and obesity prevalence. Suitable healthcare strategies and intervention programmes are needed for combating such prevalence in population. Finally, the results are important for effective implementation of any public health programme and appropriate intervention strategies to reduce the prevalence and associated risks of overweight-obesity in adults.

\section{REFERENCES}

1. World Health Organization (WHO). The Asia Pacific Perspective. Redefining Obesity and its treatment. Geneva: World Health Organization, 2000.

2. Popkin BM. The shift in stages of the nutritional transition in the developing world differs from past experiences! Public Health Nutrition 2002; 5: 205-14.

3. Hossain, P, Kawar B, Nahas ME. Obesity and diabetes in the developing world-a growing challenge. N Engl J Med 2007; 356: 213-5.

4. Monteiro CA, Conde WL, Popkin BM. Income-specific trends in Brazil:1975-2003 Am J Public Health 2007; 97: 1808-12.

5. Kapoor SK, Anand K. Nutritional transition: a public health challenge in developing countries. J Epidemiol Community Health 2002; 56: 804.

6. Subramanian SV, Smith GD. Patterns, distribution, and determinants of under- and overnutrition: a population-based study of women in India. Am J Clin Nutr 2006; 84: 633-40.

7. Bharati S, Pal M, Bhattacharya BNl. Prevalence and causes of chronic energy deficiency and obesity in Indian women. Hum Biol 2007; 79: 395-412.

8. Subramanian SV, Kawachi I, Smith GD. Income inequality and the double burden of under- and overnutrition in India. $J$ Epidemiol Community Health 2007; 61: 802-9.

9. Zargar, AH, Masoodi SR, Laway BA, Khan AK, Wani AI, Bashir MI, et al. Prevalence of obesity in adults--an epidemiological study from Kashmir Valley of Indian Subcontinent. J Assoc Physicians India 2000; 48:1170-4.

10. Dudeja V, Misra A, Pandey RM, Devina G, Kumar G, Vikram NK. BMI does not accurately predict overweight in Asian Indians in northern India. Br J Nutr, 2001; 86: $105-12$

11. Shukla HC, Gupta PC, Mehta HC, Hebert JR. Descriptive epidemiology of body mass index of an urban adult population in western India. $J$ Epidemiol Community Health, 2002;56: 876. 
12. Bhadra MA, Mukhopadhyay A, Bose K. 2005. Overweight and obesity among adult Bengalee Hindu Women of Kolkata India. Hum Ecol 2005; 13: 77-83.

13. Das M, Bose K. Presence of high rates of overweight and obesity among adult Marwaris of Howrah, West Bengal, India. Coll Antropol 2006; 30; 81-86.

14. Sarkar D, Mondal N, Sen J. Obesity and blood pressure variations among the Bengali Kayastha Population of North Bengal, India. J Life Sci 2009; 1: 35-43.

15. Wang Y, Chen HJ, Shaikh S, Mathur P. Is obesity becoming a public health problem in India? Examine the shift from under- to overnutrition problems over time. Obes Rev 2009; 10: 456-74.

16. Mungreiphy NK, Kapoor S. Socioeconomic changes as covariates of overweight and obesity among Tangkhul Naga tribal women of Manipur, North-east India. J Biosoc Sci 2010; 42: 289-305.

17. Garg C, Khan SA, Ansari SH, Garg M. 2010. Prevalence of obesity in Indian women. Obes Rev 2010; 11: 105-8.

18. Masoodi SR., Wani AA, Wani AI, et al. Prevalence of overweight and obesity in young adults aged 20-40 years in North India (Kashmir Valley). Diab Res Clin Pract 2010; 87: e4-e6.

19. Sen, J, Mondal N, Dutta S. Factors affecting overweight and obesity among urban adults: a cross-sectional study. Epidemiology Biostatistics Public Health 2013;10: e 8741 $-1-8$.

20. Stein AD, Thompson AM, Waters A. Childhood growth and chronic disease: evidence from countries undergoing the nutrition transition. Matern Child Nutr 2005; 1: $177-84$.

21. Iriart C, Handal AJ, Boursaw B. Chronic malnutrition among overweight Hispanic children: understanding health disparities. $J$ Immigr Minor Health 2011; 13:1069-75.

22. Mascie-Tylor CG, Goto R. Human variation and body mass index : a review of the university of BMI cut-offs, gender and urban -rural differences, and secular changes. J Physiol Anthropol 2007; 26: 109.

23. Mondal N, Sen J. Use of body mass index to assess nutritional status and health: a review of the studies done in India. South Asian Anthropologist 2009; 9: 13-20.

24. Khan MM, Kraemer A. Factors associated with being underweight, overweight and obese among ever-married non-pregnant urban women in Bangladesh. Singapore Med $J$ 2009; 50:804-13.

25. Wannamethee SG, Shaper AG. Alcohol, body weight, and weight gain in middle-aged men. Am J Clin Nutr 2003; 77:1312-7.

26. Sudar A. Body fatness and its social and lifestyle determinants in young working males from Cracow, Poland. J Biosoc Sci 2009; 41:139-54.

27. Pedneker MS, Hakama M, Hebert JR, Gupta PC. Association of body mass index with all cause and caus - specific mortality: findings from a prospective cohort study in Mumbai (Bombay), India. Int J Epidemiol 2008; 37: 524-35.

28. Shafique S, Akhter N, Stallkamp G, de Pee S, Panagides D, Bloem MW. Trends of underand overweight among rural and urban poor women indicate the double burden of malnutrition in Bangladesh. Int $J$ Epidemiol 2007; 36:449-57.

29. Yang, Z, Huffman SL. Nutrition in pregnancy and early childhood and associations with obesity in developing countries. Matern Child Nutr 2013; 9:105-19.

30. Chukwuonye II, Chuku A, John C, John C, Ohagwu KA, Imoh ME, et al. Prevalence of overweight and obesity in adult Nigerians - a systemic review. Diabetes Metab Syndr Obes 2013; 6: 43-7.

31. World Health Organization (WHO). Diet, nutrition and the prevention of chronic diseases. WHO Technical Report Series 916. World Health Organization, Geneva, 2002.

32. Griffiths P, Bentley M. Women of higher socio-economic status are more likely to be overweight in Karnataka, India. Eur J Clin Nutr 2005; 59:1217-20.

33. Sengupta, $S$. Tribes of North-East India: biological and cultural perspectives. New Delhi: Gyan Publication House, 1994.

34. Lwanga, SK, Lemeshow S. Sample size determination in health studies: A Practical Manual. Geneva: World Health Organization, 1991. 
35. Touitou Y, Portaluppi F, Smolensky MH, Rensing L. Ethical principles and standards for the conduct of human and animal biological rhythm research. Chronobiol Int 2004; 21:161-70.

36. Hall JG, Allanson JE, Gripp KW, Slavotinek AM. Handbook of Physical Measurements. New York: Oxford University Press, 2007.

37. Ulijaszek, SJ, Kerr DA. Anthropometric measurement error and the assessment of nutritional status. Br J Nutr 1999; 82: 165-77.

38. Praveen Kumar NVRT, Mohanta GP, Manna PK, Manavalan R. Body mass index-a diagnostic tool to assess obesity. Indian Journal Pharmacy Practice 2008; 2: 81-3

39. Singh SP, Sikri G, Garg MK. Body mass index and obesity: tailoring "cut-off" for an Asian Indian male population. Medical Journal Armed Forces India 2008; 64: 35053.

40. Mohan KBK, Sapthagirivasan V, Anburajan M. Community-Specific BMI cut-off points for South Indian females. Journal Obesity 2011;doi:10.1155/2011/292503.

41. Piperata BA. Nutritional status of Ribeirinhos in Brazil and nutrition transition. Am J Phys Anthropol 2007; 133:868-78.

42. Sidhu, SH. Kaur T. Prevalence of overweight and obesity among adult urban female of Punjab: a cross-sectional study. The Anthropologist 2000; 1: 101-3.

43. International Association for the Study of Obesity (IASO). Global Prevalence of adult obesity. London, 2010. (accessed: $18^{\text {th }} \mathrm{July,}$ 2012; available: www.iotf.org/..../ Global Prevalence of Adult Obesity $10^{\text {th }}$, February, 2010.pdf).

44. Pardo Silva MC, De Laet C, Nusselder WJ, Peeters A. Adult obesity and number of years lived with and without cardiovascular disease. Obesity (Silver Spring) 2006; 14:1264-73.

45. Rosmond R. Aetiology of obesity: a striving after wind? Obes Rev 2004; 5: 177-81.

46. Proper KI, Cerin E, Brown WJ, Owen N. Sitting time and socio-economic differences in overweight and obesity. Int J Obes (Lond) 2007; 31: 169-76.
47. Al-Mahroos F, Al-Roomi K. Obesity among adult Bahraini population: impact of physical activity and educational level. Ann Saudi Med 2001; 21:183-7.

48. Gutiérrez-Fisac JL, Banegas JR, Artalejo FR, Increasing prevalence of overweight and obesity among Spanish adults, 1987-1997. Int J Obes Relat Metab Disord 2000; 24: 167782.

49. Jeffery RW, Rick AM. Cross-sectional and longitudinal associations between body mass index and marriage-related factors. Obes Res 2002; 10: 809-15.

50. Tur JA, Serra-Majem L, Romaguera D, Pons A. Profile of overweight and obese people in a Mediterranean region. Obes Res 2005; 13: 527-36.

51. Azmi M Y Jr, Junidah R, Siti Mariam A, et al. Body Mass Index (BMI) of adults: Findings of the Malaysian Adult Nutrition Survey (MANS). Malays J Nutr 2009; 15: 97-119.

52. Dickerson JB, Smith ML, Benden ME, Ory MG. The association of physical activity, sedentary behaviors, and body mass index classification in a cross-sectional analysis: are the effects homogenous? BMC Public Health 2011; 11: 926 doi:10.1186/1471-2458-11926

53. Vaidya AK, Pokharel PK, Nagesh S, Karki P, Kumar S, Majhi S . 2006. Association of obesity and physical activity in adult males of Dharan, Nepal. Kathmandu Univ Med J 2006; 4:192-7.

54. Yeomans, MR. Alcohol, appetite and energy balance: is alcohol intake a risk factor for obesity? Physiol Behav 2010; 100:82-9.

55. Ade J, Rohrer NJ, Rea NK. Immigration, income, drinking and obesity in African American adults. J Immigr Minor Health 2011; 13:659-63.

56. Ahn S, Zhao H, Tai-Seale $\mathrm{M}$, et al. The longitudinal effects of behavioral, health, and socio-demographic factors on body mass index among older Chinese adults. Int $J$ Public Health 2012; 57: 269-77. 
57. Koster A, Leitzmann MF, Schatzkin A, et al. The combined relations of adiposity and smoking on mortality. Am J Clin Nutr 2008; 88: 1206-12.
58. Fang H, Ali MM, Rizzo JA. Does smoking affect body weight and obesity in China? Econ Hum Biol 2009; 7: 334-50. 